\title{
Genetic Diversity Analysis for Some Desi Type Chickpea (Cicer arietinum L.) Advanced Lines Under Potential Environment of North Gondar, Ethiopia
}

\author{
Amare Tsehaye ${ }^{1, ~ *}$, Asnake Fikre ${ }^{2}$ \\ ${ }^{1}$ Gondar Agricultural Research Center, Gondar, Ethiopia \\ ${ }^{2}$ Ethiopian Institute of Agricultural Research, Addis Ababa, Ethiopia
}

Email address:

amaretsehay1@gmail.com (A. Tsehaye)

${ }^{*}$ Corresponding author

\section{To cite this article:}

Amare Tsehaye, Asnake Fikre. Genetic Diversity Analysis for Some Desi Type Chickpea (Cicer arietinum L.) Advanced Lines Under Potential Environment of North Gondar, Ethiopia. American Journal of Bioscience and Bioengineering. Vol. 8, No. 2, 2020, pp. $27-35$. doi: $10.11648 /$ j.bio.20200802.12

Received: April 24, 2020; Accepted: May 18, 2020; Published: June 8, 2020

\begin{abstract}
The present study was conducted in 100 promising chickpea (Cicer arietinum L.) genotypes using Mahalanobis $\mathrm{D}^{2}$ Statistics. The divergence $\left(\mathrm{D}^{2}\right)$ analysis revealed that the 100 chickpea genotypes were grouped into nine significant clusters. The intra-cluster distance values were ranged from 5.3 (cluster IV) to 77.8 (cluster VIII). The highest inter cluster distance were observed between genotypes of cluster I and cluster VIII (874.5) followed by cluster I and cluster II (837.4), cluster I and cluster V (759.3), cluster I and cluster III (480.4), cluster I and cluster VII (413.7), cluster IV and cluster VIII (390.9), cluster II and cluster IV (377.5) and Cluster II and cluster VI (309.4), cluster I and cluster IX (300.4), cluster I and cluster IV (295.2), cluster IV and cluster V (287.2). The lowest inter cluster distance (81.6) were found between cluster VI and cluster IX followed by cluster II and cluster VII (81.8), cluster III and cluster VII (87.4), cluster IV and cluster VI (90.6), cluster II and cluster III (93.6), indicating existence of closer proximity between these clusters. Based on inter cluster distances and Per se performance, hybridization among the genotypes from these clusters which showed maximum distance might produce high yielding varieties having broad genetic base. In general the genotypes JV-11, IE-16-059/1, iccx-090013-f2-p215-BP, DZ-2012-CX-0028, iccx-060045-f3-p5-BP, iccx-060039-f3-p182-BP may serve as potential parents for grain yield. IE-16-109/2, iccx-0900013-f2-p107-BP, icc-6279, JG-62, icc-15614, IE-16-059/2 can be also a parental line for earliness, while iccx-090013-f2-p265-BP, iccx-090013-f2-p107-BP, iccx090013-f2-p103-BP, iccx-090013-f2-p215-BP for hundred seed weight. IE-16-109/2, icc-14778, icc-510, DZ-2012-CK-0253, icc5135 also be a potential parental line for quality character of crude protein. Generally genotypes listed above may serve as a parental lines for hybridization program in the improvement of chickpea grain yield and its contributing trait.
\end{abstract}

Keywords: Chickpea, Cluster Analysis, D² Statistics, Inter Cluster Distance and Intra Cluster Distance

\section{Introduction}

\subsection{Background and Justification}

Pulse crops play as a driver in the home of agriculture for economic growth and food security. It occupies approximately $13 \%$ of cultivated land and account for approximately $10 \%$ of the agricultural value addition. They are also contribute much more for smallholder in income generation, since high value crop than cereals, and it is a cost effective source of protein that accounts for approximately $15 \%$ of protein intake [3].
Pulses, such as chickpea (Cicer arietinum L.), as dry seeds of leguminous, are an important sources of human regimen throughout the world. Chickpea is the most important pulse crop in Ethiopia. The bulk of the crop variety in the country is dominated by the sweet Desi type and the Kabuli type is also grown in limited areas. In Ethiopia chickpeas are consumed widely fresh as green vegetables, sprouted, fried roasted and boiled. It is also ground into flour to make baby feed mixed with other cereals, soup bread and meat. It is also used to rehabilitate depleted fallow lands through utilizing crop rotation system [15]. 
The genetic diversity of genotypes makes them an important resource of genes for breeding programs, developing new farming systems, diversification of production and new quality products [9]. Information about genetic diversity helps the selection of parental genotypes from random populations. Accurate estimation of the levels and patterns of genetic diversity is useful to estimate the potential of heterotic combinations before attempting crosses and hence saving time and resources [6]. Such information can serve for introgression of desirable genes from wild germplasm to the high yielding germplasm resource, analysis of genetic variability in germplasm and identification of different combinations for creating segregating progenies with greatest genetic variability [2]. Estimate the level of genetic variability and determine the significance of traits are important for further trait discovery, intercrossing design, economic trait detection and good parental lines establishment.

Genetic variability refers the genetic differences within or among genotypes. Genetic variability has great importance for the survival of a species. When a population of an organism contains a large gene pool, the genetic blueprints of individuals in the population vary significantly and the group has a greater chance of surviving and flourishing than a population with limited genetic variability because some of the individuals may have inherited traits making them particularly resistant to biotic and abiotic factors. The more genetic variability present within species or populations, the higher the likelihood that at least some of the individuals will be resistant to biotic and abiotic factor, high yielder, and most economical like in nutrient use efficiency [16].

The major constraints to chickpea productivity are biotic stresses like ascochyta blight, pod borer, cut worm and fusarium wilt, abiotic stresses like drought, extreme temperatures and salinity. Chickpea has high variation for various qualitative and quantitative traits i.e. grain color and shape, color of flower, pod number, seed coat color, earliness, insect pest resistance, that can help breeders to develop or select superior lines and varieties. For maintenance and efficient utilization of germplasm, it is important to investigate the extent of genetic variability and its magnitude for the determination of the success of a breeding program [13]. The efficiency of selection depends on the identification of genetic variability from the phenotypic expression of the characters.

The success of good breeding program usually depends upon the genetic variability present in the breeding materials, so assessment of genetic variability in the base population should have to be prior action in breeding program. Information on the relative magnitude of different sources of variation among different genotypes for several traits helps in measurement of their range of genetic diversity. The genetically diverse genotypes are likely to produce heterotic effect and superior segregate when incorporated in hybridization to hasten crop improvement program. Thus, knowledge on genetic variability, heritability and genetic advance is essential for a breeder to choose and for efficient utilization of better genotypes for crop improvement programs [8]. However, spatial and temporal studies on the amount, kind and magnitude of variability as well as genetic relationship of traits are not efficiently exploited. Thus, the purposes of this study were to estimate the total genotypic variability presented among germplasms under the study and to determine the association among traits.

\subsection{Objective of the Study}

\subsubsection{General Objective}

To asses and quantify the level of genetic diversity presented among tested chickpea germplasm lines

\subsubsection{Specific Objectives}

The study was proposed aiming at the following specific objectives

1) To determine the level of genetic diversity among examined chickpea genotypes.

2) To identify genotypes with higher/special level of significance for the breeding program.

\section{Materials and Methods}

\subsection{Description of the Study Area}

The experiment was conducted at Mekonta farm site in Takusa district, North Gondar, Ethiopia. The area is located at $12^{\circ} 0^{\prime} 50^{\prime \prime}$ to $12^{\circ} 23^{\prime} 40^{\prime \prime}$ northern latitude and $36^{\circ} 24^{\prime}$ $28^{\prime \prime}$ to $37^{\circ} 6^{\prime} 58^{\prime \prime}$ east longitude with an altitude of 1780 meter above sea level with annual rainfall of $730 \mathrm{~mm}$. The average temperature of the areas is $21.65^{\circ} \mathrm{C}$. The major crops grown widely are chickpea, tef, maize, spice crops (cumin, hot pepper, tomato), etc., under rain fed and irrigation but cereal mono cropping is the predominant crop grown in the study area [17]. The soil type of the area is light vertisol with a $\mathrm{pH}$ ranging from 6.5 to 8.0. The field was loose tilt and well drained. The stubble and debris from the previous crop was removed. A rough seedbed was prepared to avoid packing of the cloddy surface due to winter rains and to facilitate soil aeration and for easy seedling emergence [1].

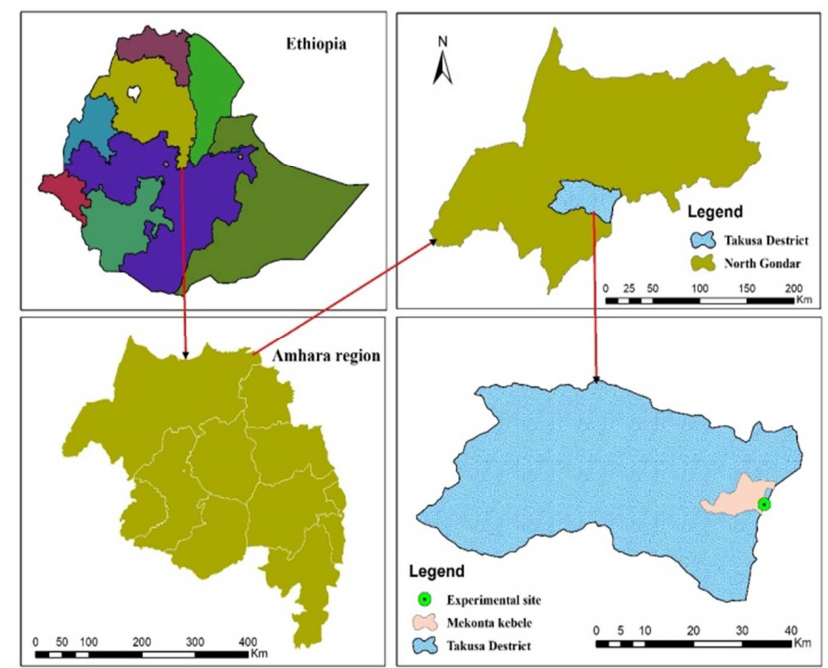

Figure 1. Study area map of experimental site Takusa district, North Gondar, Ethiopia. 


\section{Climate data for the experimental area}

Takusa district is the key growing areas of chickpea in Ethiopia. The area received a long term mean annual rainfall of $1097 \mathrm{~mm}$ with a mean annual temperate of $23^{\circ} \mathrm{C}$ (min $16^{\circ} \mathrm{C}$ and $\left.\max 30^{\circ} \mathrm{C}\right)$. The experimental area received $1217 \mathrm{~mm}$ mean annual rain fall with $22^{\circ} \mathrm{C}\left(\min 13.27^{\circ} \mathrm{C}\right.$ and $\max 30.6^{\circ} \mathrm{C}$ ) mean annual temperature during the growing season in 2018 .

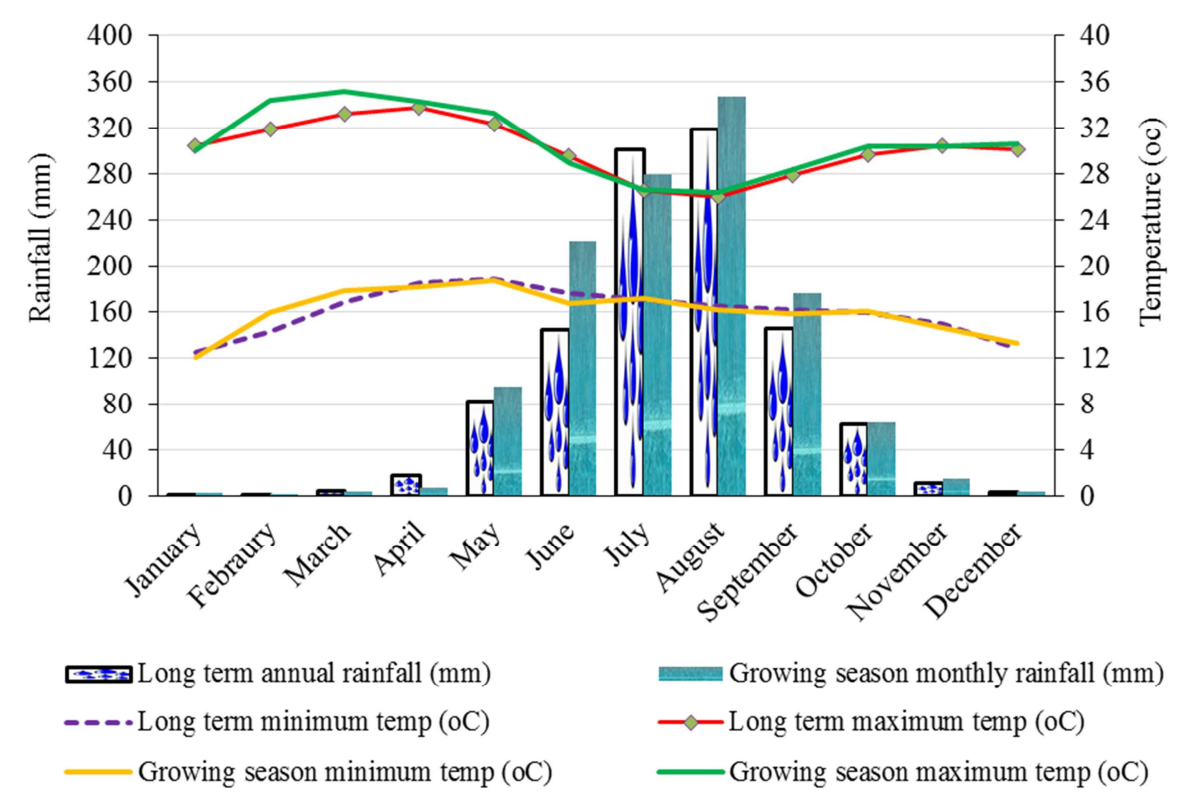

Figure 2. Graph showing long term (1987-2018) and growing season (2018) climate data.

\subsection{Experimental Materials}

A total of 100 advanced lines of Desi type chickpea germplasms were evaluated in 2018/19 main cropping season at Mekonta farm site, Takusa district, North Gondar, Ethiopia
The genotypes were acquired from Debre Zeit agricultural Research Center, Ethiopia. The list of genotypes is given below (Table 1).

Table 1. List of genotypes used in the present investigation.

\begin{tabular}{|c|c|c|c|c|c|c|c|}
\hline Code & Genotype Name/pedigree & Code & Genotype Name/pedigree & Code & Genotype Name/pedigree & Code & $\begin{array}{l}\text { Genotype } \\
\text { Name/pedigree }\end{array}$ \\
\hline G-1 & iccx-060045-f3-p12-BP & G-26 & iccu-11108 & G-51 & icc-4958 & G-76 & iccx-060039-f3-p10-BP \\
\hline G-2 & Iccx-090013-f2-p147-BP & G-27 & DZ-2012-CX-20115-0041 & G-52 & iccx-060045-f3-p11-BP & G-77 & iccril-03-0167 \\
\hline G-3 & IE-16-012/2 & G-28 & iccx-060039-f3-p2015-BP & G-53 & iccx-060045-f3-p165-BP & G-78 & iccx-090013-f2-p245-BP \\
\hline G-4 & iccx-060039-f3-p196-BP & G-29 & iccx-060045-f3-p5-BP & G-54 & IE-16-025/1 & G-79 & icc-15762 \\
\hline G-5 & icc-1164 & G-30 & icc-1422 & G-55 & iccx-090013-f2-p129-BP & G-80 & DZ-2012-CX-0028 \\
\hline G-6 & iccx-060039-f3-p39-BP & G-31 & DZ-2012-ck-20115-50045 & G-56 & icc-67 & G-81 & iccx-060045-f3-p157-BP \\
\hline G-7 & IE-16-094/1 & G-32 & iccx-090013-f2-p120-BP & G-57 & IE-16-003/1 & G-82 & icc-4533 \\
\hline G-8 & DZ-2012-CK-0253 & G-33 & iccx-090013-f2-p3-BP & G-58 & iccx-090013-f2-p234-BP & G-83 & iccx-060039-f3-p107-BP \\
\hline G-9 & icc-14778 & G-34 & iccx-090013-f2-p145-BP & G-59 & DZ-2012-CK-20115-16-0058 & G-84 & icc-13863 \\
\hline G-10 & IE-16-079/1 & G-35 & DZ-2012-CK-0040 & G-60 & iccx-090013-f2-p107-BP & G-85 & iccx-060045-f3-p130-BP \\
\hline G-11 & iccx-060039-f3-p174-BP & G-36 & 090013-f2-p276-BP & G-61 & iccx-060039-f3-p178-BP & G-86 & icc-510 \\
\hline G-12 & icc-15888 & G-37 & IE-16-109/2 & G-62 & iccx-060045-f3-p173-BP & G-87 & iccx-0900013-f2-p115-BP \\
\hline G-13 & iccril-04-0087 & G-38 & iccx-090013-f2-p105-BP & G-63 & iccx-090013-f2-p265-BP & G-88 & $J V-11$ \\
\hline G-14 & DZ-2012-CK-240 & G-39 & iccx-090013-f2-p215-BP & G-64 & icc-6279 & G-89 & Local \\
\hline G-15 & Natoli & G-40 & iccx-060039-f3-p173-BP & G-65 & icc-15294 & G-90 & iccx-060045-f3-p197-BP \\
\hline G-16 & iccx060045-f3-p98-BP & G-41 & iccu-115 & G-66 & iccx-060045-f3-p76-BP & G-91 & DZ-2012-CX-0227 \\
\hline G-17 & iccx060039-f3-p21-BP & G-42 & DZ-2012-ck-0238 & \multicolumn{2}{|c|}{ icc-14199xnatoli-p137 } & G-92 & iccx-060045-f3-p91-BP \\
\hline G-18 & iccx-060039-f3-p182-BP & G-43 & JG-62 & G-68 & DZ-2012-CX-0048 & G-93 & iccx-060039-f3-p204-BP \\
\hline G-19 & IE-16-059/2 & G-44 & iccx-060039-f3-p57-BP & G-69 & iccx-060039-f3-p270-BP & G-94 & iccx-060039-f3-p24-BP \\
\hline G-20 & iccx-060039-f3-p145-BP & G-45 & Dimtu & G-70 & icc-10673 & G-95 & icc-5135 \\
\hline Code & Genotype name/pedigree & Code & Genotype name/pedigree & Code & Genotype name/pedigree & Code & Genotype name/pedigree \\
\hline G-21 & DZ-2012-CK-0048 & G-46 & iccx-060039-f3-p131-BP & G-71 & iccx-0900013-f2-p107-BP & G-96 & iccx-060045-f3-p253-BP \\
\hline G-22 & iccx-060039-f3-p188-BP & G-47 & iccx-060045-f3-p132-BP & G-72 & iccu-07103 & G-97 & iccril-03-0215 \\
\hline G-23 & DZ-2012-CK-0030 & G-48 & iccu-090013-f2-p108-BP & $\mathrm{G}-73$ & Dalota & G-98 & iccx-060045-f3-p126-BP \\
\hline G-24 & iccx-090013-f2-p103-BP & G-49 & iccril-03-0127 & G-74 & iccx-060045-f3-p232-BP & G-99 & iccx-060045-f3-p102-BP \\
\hline G-25 & DZ-2012-CK-0239 & G-50 & IE-16-059/1 & G-75 & icc-15614 & G-100 & iccu-94954 \\
\hline
\end{tabular}




\subsection{Experimental Design and Field Management}

The experiment was laid out in triple lattice design with three replications. Each genotype had 2 rows in a plot of $2 \mathrm{~m}$ length with a row to row and plant to plant spacing of $30 \mathrm{~cm}$ and $10 \mathrm{~cm}$ respectively. Each genotype was assigned to each plot randomly. A seed of $100 \mathrm{~kg} / \mathrm{ha}$ was used. $121 \mathrm{~kg}$ NPS $\left(23 \mathrm{~N}, 46 \mathrm{P}_{2} \mathrm{O}_{5}\right.$, and $\left.8.4 \mathrm{~S}\right)$ fertilizer was applied. All the recommended crop management practices have been accomplished based on the recommendation.

\subsection{Data Collected}

Five plants per genotypes were selected randomly for recording plant based characters and net plot area for plot based characters following the ICRISAT descriptor.

1. Days to flowering (DF): Number of days from planting to $50 \%$ of plants bears flower

2. Days to physiological maturity (DM): The number of days from sowing to the stage when $90 \%$ of the plants in a plot have reached physiological maturity.

3. Seed filling period (SFP): The number of days from flowering to maturity (i.e. the number of days to maturity minus the number of days to flowering).

4. Hundred seed weight (HSW) (g): The weight of hundred seeds taken randomly from the harvest seed lots of each plot.

5. Grain yield (GY): Grain yield $\left(\mathrm{kgha}^{-1}\right)$ from the specified net plot area and adjusted to its recommended $(10 \%)$ moisture content.

6. Above ground biomass (BM): the weight of the above ground mass including seed $\left(\mathrm{kgha}^{-1}\right)$ of chickpea in specified net plot area as soon as harvesting.

7. Harvest index (HI): calculated as the ratio of grain yield to above ground biological yield.

8. Number of pods per plant (NPP): Average of actual count of five plants pod.

9. Number of seeds per pod (NSP): five random pods were crushed for each five random plants, counting the total seed and divided for number of pod and number of plant.

10. Plant height $(\mathrm{PH})(\mathrm{cm})$ : The average height of five plants taken randomly from each plot measured at physiological maturity starting from ground to tip of the shoot.

11. Number of primary branches (NPB): Average of actual count of primary branches on the main stem per plant.

12. Number of secondary branches (NSB): Average of number of branches arising directly from primary branches.

13.Protein content (\%)

\subsection{Data Analysis}

\subsubsection{Genetic Distance and Cluster Analysis}

Cluster analysis is a group of multivariate techniques whose primary purpose is to group objects (e.g., respondents, products, or other entries) based on the characteristics they possess. It is a means of grouping genotypes based upon attributes that make them similar. Data of five plants from each genotype was averaged replication wise and mean data was used for statistical analysis. Clustering pattern among 100 chickpea genotypes was assessed by using Tocher's method [14]. Average intra- (diagonal) and inter-cluster distance was estimated by using Tocher's method representing Euclidean distances considering yield and its ten contributing traits in chickpea genotypes.

The generalize distance between two population is defined by $[11,12]$ as folws.

$$
\mathrm{D}^{2}=\lambda_{\mathrm{ij}} \cdot \sigma_{\mathrm{i}} \cdot \sigma_{\mathrm{j}}
$$

Where, $\lambda_{\mathrm{ij}}=$ reciprocal matrix to the common dispersion matrix

$\sigma_{\mathrm{i}}=$ difference between the mean values of two populations for $\mathrm{i}^{\text {th }}$ character

$\sigma_{j}=$ difference between the mean values of two populations for $\mathrm{j}^{\text {th }}$ character

\subsubsection{Determination of Genetic Distance}

Formal rules can't be laid down for finding the clusters because a cluster is not a well-defined term the only criteria appears to be that any two groups belonging to the same cluster should at least on an average show a smaller $\mathrm{D}^{2}$ than those belonging to the two different clusters. Tocher method described by [14] is to start with the two closely associated groups and find a third group which has the smallest $\mathrm{D}^{2}$ from the two. Similarly the fourth is chosen to have the smallest $\mathrm{D}^{2}$ from the first three and so on if at any stage the average $\mathrm{D}^{2}$ of the group from those already listed appears to be high, then this group does not fit in the former groups and is therefore taken outside the former cluster. The group of first cluster are then omitted and rest are treated similarly it is also useful to calculate the change in average $\mathrm{D}^{2}$ within a cluster due to inclusion of an additional group if the changes are appreciable, then the newly added group has to be considered as outside the cluster.

Average intra and inter cluster $\mathrm{D}^{2}$ and $\mathrm{D}$ values

1) Average intra cluster $D^{2}$

$\mathrm{D} 2=\sum \mathrm{Di}^{2} / \mathrm{n}$, where, $\sum \mathrm{D}^{2} \mathrm{i}$ is sum of distances between all possible combinations ( $\mathrm{n}$ ) is the population included in a cluster.

2) Average inter cluster $D^{2}$

$$
D^{2}=\Sigma D^{2} i / n_{i} \cdot n_{j}
$$

Where, $n_{i}=$ number of population in cluster $i, n_{j}=$ number of population in cluster $\mathrm{j}$

\subsubsection{Cluster Means}

Cluster means were calculated for individual character on the basis of mean performance of the genotypes included within the cluster.

\subsubsection{Principal Component Analysis}

Principal component analysis (PCA) was used to find out the characters, which accounted more to the total variation. 
The data were standardized to mean zero and variance of one before computing principal component analysis. Principal components were calculated using SAS computer software based on the following formula.

The first PCA value (Y1) is given by the linear combination of the variables $\mathrm{X} 1, \mathrm{X} 2 \ldots \mathrm{Xp}$

$$
\mathrm{Y} 1=\mathrm{a} 11 \mathrm{X} 1+\mathrm{a} 12 \mathrm{X} 2+\ldots+\mathrm{a} 1 \mathrm{pXp}
$$

The second principal component is calculated in the same way,

$$
\mathrm{Y} 2=\mathrm{a} 21 \mathrm{X} 1+\mathrm{a} 22 \mathrm{X} 2+\ldots+\mathrm{a} 2 \mathrm{pXp}
$$

This continues until a total of $p$ principal components have been calculated, equal to the original number of variables. At this point, the sum of the variances of all of the principal components will equal the sum of the variances of all of the variables.

\section{Result and Discussion}

\subsection{Divergence $\left(D^{2}\right)$ and Cluster Analysis}

Genetic divergence in 100 genotypes of chickpea were measured following the procedure of Mahalanobis (1936) D2 statistic (Table 2). The genotypes were categorized into nine distinct significant clusters using Tocher's method of $\mathrm{D}^{2}$ statistics (Table 2 and Figure 3).

\subsubsection{Inter and Intra Cluster Divergence $D^{2}$ Analysis}

The divergence $\left(\mathrm{D}^{2}\right)$ analysis revealed that the 100 chickpea genotypes were grouped into 9 significant clusters (Table 2). The intra-cluster distance values were ranged from 5.3 (cluster IV) to 77.8 (cluster VIII). More than $66 \%$ of the intra cluster distance were greater than $53.5 \mathrm{D}^{2}$ value, indicated that there were diversification within groups. The highest inter cluster distance were observed between genotypes of cluster I and cluster VIII (874.5) followed by cluster I and cluster II (837.4), cluster I and cluster V (759.3), cluster I and cluster III (480.4), cluster I and cluster VII (413.7), cluster IV and cluster VIII (390.9), cluster II and cluster IV (377.5) and Cluster II and cluster VI (309.4), cluster I and cluster IX (300.4), cluster I and cluster IV (295.2), cluster IV and cluster V (287.2). The lowest inter cluster distance (81.6) were found between cluster VI and cluster IX followed by cluster II and cluster VII (81.8), cluster III and cluster VII (87.4), cluster IV and cluster VI (90.6), cluster II and cluster III (93.6), indicating existence of closer proximity between these clusters (Table 2). Based on [4] information, 360 chickpea lines were analyzed in $\mathrm{D}^{2}$ statistics and classified in to 9 clusters. 365 genotypes were evaluated and found six significant clusters [13]. Also [16] investigated and found 16 clusters, indicating the presence of wide genetic diversity indicated that breeders can improve chickpea productivity only through simple selection.

\begin{tabular}{|c|c|c|c|c|c|c|c|c|c|}
\hline Cluster & I & II & III & IV & V & VI & VII & VIII & IX \\
\hline I & 61.6 & 837.4 & 480.4 & 295.2 & 759.3 & 309.4 & 413.7 & 874.5 & 300.4 \\
\hline II & & 76.5 & 93.6 & 377.5 & 112.7 & 195.3 & 81.8 & 97.9 & 194.1 \\
\hline III & & & 48.9 & 161.7 & 108.9 & 103.1 & 87.4 & 99.1 & 101.6 \\
\hline IV & & & & 5.3 & 287.2 & 90.6 & 183.6 & 390.9 & 98.2 \\
\hline V & & & & & 65.9 & 168.2 & 97.6 & 119.9 & 166.4 \\
\hline VI & & & & & & 21.9 & 96.0 & 203.4 & 81.6 \\
\hline VII & & & & & & & 53.3 & 104.7 & 95.4 \\
\hline VIII & & & & & & & & 77.8 & 202.2 \\
\hline IX & & & & & & & & & 21.2 \\
\hline
\end{tabular}

Table 2. Intra (diagonal) and inter (off diagonal) cluster D2 values of 100 chickpea genotypes grown under potential environments of North Gondar.

$\mathrm{X}^{2}=26.12$ at $1 \%$ probability level and $\mathrm{X}^{2}=21.03$ at $5 \%$ probability level

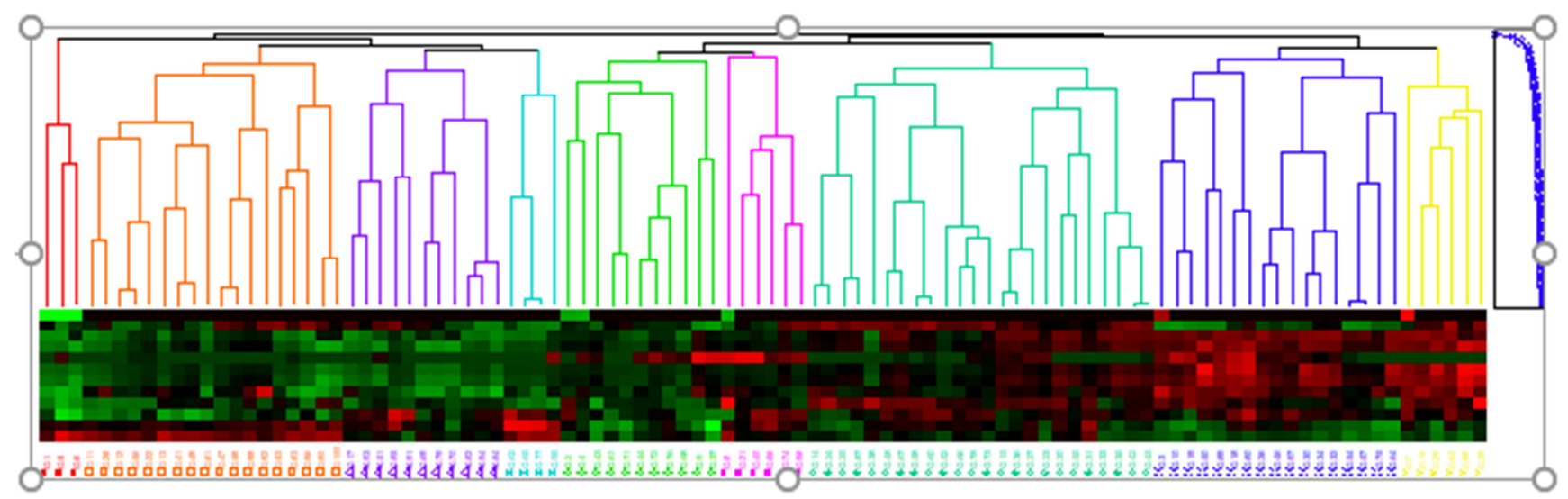

Figure 3. Dendrogram showing the genetic relationship among the 100 chickpea genotypes. 


\subsubsection{Grouping of Genotypes in to Different Clusters}

Composition of the clusters revealed that cluster VII has the largest cluster consisting of 24 genotypes, followed by cluster II consisting of 18 genotypes, cluster VIII consisting of 17 genotypes, cluster III and V consisting about 11 genotypes. While the smallest number were consisted in cluster I followed by cluster IV, VI, and IX (3 genotype, 4 genotype, 6 genotype and 6 genotype) respectively (Table 3 ).

Table 3. Distribution of 100 chickpea genotypes in different clusters.

\begin{tabular}{|c|c|c|}
\hline $\begin{array}{l}\text { cluster } \\
\text { number }\end{array}$ & $\begin{array}{l}\text { number of } \\
\text { cluster }\end{array}$ & Genotype included in the cluster \\
\hline I & 3 & iccx-060045-f3-p12-BP, icc-1164, iccx-060039-f3-p39-BP \\
\hline II & 18 & $\begin{array}{l}\text { iccx-060039-f3-p174-BP, icc-15888, iccril-04-0087, iccx-060039-f3-p188-BP, iccx-060039-f3-p2015-BP, iccu-115, iccx- } \\
\text { 060045-f3-p132-BP, iccril-03-0127, iccx-060045-f3-p165-BP, icc-67, DZ-2012-CK-20115-16-0058, iccx-060045-f3- } \\
\text { p157-BP, iccx-060039-f3-p107-BP, iccx-060045-f3-p197-BP, iccx-060045-f3-p91-BP, iccx-060045-f3-p253-BP, iccx- } \\
\text { 060045-f3-p102-BP, iccu-94954 }\end{array}$ \\
\hline III & 11 & $\begin{array}{l}\text { iccx060039-f3-p21-BP, icc-4958, iccx-060039-f3-p270-BP, icc-10673, icc-15762, icc-4533, icc-13863, iccx-060045-f3- } \\
\text { p130-BP, DZ-2012-CX-0227, iccx-060039, f3-p204-BP, iccx-060039-f3-p24-BP }\end{array}$ \\
\hline IV & 4 & iccx-060045-f3-p173-BP, icc-15294, iccril-03-0167, icc-5135 \\
\hline $\mathrm{V}$ & 11 & $\begin{array}{l}\text { Iccx-090013-f2-p147-BP, iccx-060039-f3-p196-BP, icc-14778, IE-16-109/2, JG-62, iccx-060039-f3-p57-BP, iccx-060039- } \\
\text { f3-p178-BP, DZ-2012-CX-0048, iccx-0900013-f2-p107-BP, iccu-07103, iccx-060039-f3-p10-BP }\end{array}$ \\
\hline VI & 6 & DZ-2012-CK-0253, DZ-2012-CK-0048, iccx-060039-f3-p173-BP, iccx-060045-f3-p232-BP, icc-510, iccx-060045-f3-p126-BP \\
\hline & & $\begin{array}{l}\text { DZ-2012-CK-240, Natoli, iccx-060039-f3-p145-BP, DZ-2012-CK-0030, iccx-090013-f2-p103-BP, DZ-2012-CK-0239, } \\
\text { DZ-2012-CX-20115-0041, DZ-2012-ck-20115-50045, iccx-090013-f2-p3-BP, DZ-2012-CK-0040, iccx-090013-f2-p276- }\end{array}$ \\
\hline VII & 24 & $\begin{array}{l}\text { BP, iccx-090013-f2-p105-BP, DZ-2012-ck-0238, Dimtu, iccu-090013-f2-p108-BP, iccx-060045-f3-p11-BP, iccx-090013- } \\
\text { f2-p129-BP, iccx-090013-f2-p234-BP, iccx-090013-f2-p107-BP, iccx-060045-f3-p76-BP, icc-14199xnatoli-p137, Dalota, } \\
\text { iccx-090013-f2-p245-BP, iccx-0900013-f2-p115-BP }\end{array}$ \\
\hline VIII & 17 & $\begin{array}{l}\text { IE-16-012/2, IE-16-079/1, iccx-060039-f3-p182-BP, IE-16-059/2, iccu-11108, icc-1422, iccx-090013-f2-p120-BP, iccx- } \\
\text { 090013-f2-p145-BP, iccx-060039-f3-p131-BP, IE-16-059/1, IE-16-025/1, IE-16-003/1, icc-6279, icc-15614, DZ-2012- } \\
\text { CX-0028, Local, iccril-03-0215 }\end{array}$ \\
\hline IX & 6 & IE-16-094/1, iccx060045-f3-p98-BP, iccx-060045-f3-p5-BP, iccx-090013-f2-p215-BP, iccx-090013-f2-p265-BP, JV-11 \\
\hline
\end{tabular}

\subsubsection{Cluster Mean Analysis}

The cluster mean for different traits (Table 4), indicated wide range of variation for all the characters under the study. The highest and lowest mean value for grain yield were recorded from cluster IX (4429.3 $\left.\mathrm{kgha}^{-1}\right)$ and cluster I $\left(1126.6 \mathrm{kgha}^{-1}\right)$ respectively. The genotype found in cluster IX showed the highest above ground biomass, number of pod per plant, number of secondary branch, number of primary branch, plant height and harvest index, while the lowest were from genotypes in cluster I, however they were protein rich genotypes. The lowest and highest mean value for days to flowering were recorded from genotypes in cluster IX and I respectively. The maximum maturity days were recorded from genotypes in cluster IV, while the minimum was from cluster V. The longest and shortest grain filling period were recorded from genotypes in cluster IV and I respectively. The maximum plant height was from cluster IX and the lowest was from genotypes in cluster I. The maximum number of primary branch, secondary branch and number of pod per plant were recorded from genotypes in cluster IX, while all the reverse were from genotypes in cluster I. The largest mean value of hundred seed weight were registered from genotypes in cluster VII, while the smallest mean value were from cluster IV. Therefore, hybridization between genotypes accounted wide genetic variance is likely to be effective for developing extreme divergent heterotic cross combination. Therefore chickpea genotypes has to be earnestly exploited spatially and temporarily in breeding programs [2].

Table 4. Cluster means for yield and its contributing traits of chickpea genotypes grown under potential growing areas.

\begin{tabular}{|c|c|c|c|c|c|c|c|c|c|c|c|c|c|}
\hline Characters & DF & DM & SFP & $\begin{array}{l}\text { PH } \\
(\mathrm{cm})\end{array}$ & NPB & NSB & NPP & NSP & $\begin{array}{l}\text { BM } \\
\text { (kg/ha) }\end{array}$ & HI & $\begin{array}{l}\text { HSW } \\
\text { (g) }\end{array}$ & $\begin{array}{l}\text { GY } \\
\text { (kg/ha) }\end{array}$ & $\mathbf{C P}$ \\
\hline Cluster I & 69.1 & 118.2 & 49.1 & 29.6 & 1.3 & 2.9 & 27.3 & 1.1 & 3125.9 & 0.37 & 17.7 & 1126.6 & 16 \\
\hline Cluster II & 65.7 & 119.0 & 53.4 & 36.9 & 2.3 & 4.6 & 37.1 & 1.0 & 4541.0 & 0.39 & 23.9 & 1765.0 & 15 \\
\hline Cluster III & 55.8 & 117.0 & 61.2 & 36.0 & 1.8 & 3.7 & 31.8 & 1.0 & 3608.8 & 0.38 & 22.2 & 1350.7 & 15 \\
\hline Cluster IV & 67.3 & 131.0 & 63.8 & 31.9 & 2.1 & 4.7 & 38.3 & 1.1 & 4552.8 & 0.37 & 14.4 & 1695.0 & 15 \\
\hline Cluster V & 52.9 & 109.2 & 56.3 & 36.3 & 2.3 & 5.5 & 42.5 & 1.3 & 5387.1 & 0.40 & 18.6 & 2189.2 & 16 \\
\hline Cluster VI & 58.3 & 120.1 & 61.8 & 41.0 & 2.5 & 5.8 & 43.8 & 1.6 & 5720.9 & 0.41 & 22.8 & 2378.1 & 16 \\
\hline Cluster VII & 55.1 & 115.1 & 59.9 & 43.9 & 2.6 & 7.1 & 52.8 & 1.1 & 6678.2 & 0.46 & 29.2 & 3075.5 & 16 \\
\hline Cluster VIII & 50.8 & 111.4 & 60.6 & 41.0 & 3.0 & 9.2 & 74.3 & 1.3 & 7998.0 & 0.49 & 16.5 & 3961.5 & 15.6 \\
\hline Cluster IX & 51.7 & 113.2 & 61.4 & 46.9 & 3.3 & 10.5 & 90.3 & 1.0 & 8920.5 & 0.50 & 27.9 & 4429.3 & 14.8 \\
\hline
\end{tabular}

Note: DF: days to flowering, DM: days to maturity, SFP: seed filling period, PH (cm): plant height in centimeter, NPB: number of primary branch, NSB: number of secondary branch, NPP: number of pod per plant, NSP: number of seed per pod, BM (kg/ha): above ground biomass in kilogram per hectare, HI: harvest index, GY (kg/ha); grain yield in kilogram per hectare, HSW (g): hundred seed weight in gram and CP: crude protein. 


\subsection{Principal Components Analysis}

The principal component analysis (PCA) is important for the reflection of the highest contributor to the total variation at each axis of differentiation. The Eigen values from PCA are used for determination of how many factors to retain. In the present investigation, only the first four principal components with Eigen values greater than one based on methods proposed by [10] were used and cumulatively they explained $81.5 \%$ variability. The first PCA1 explained $49.5 \%$, PCA2 showed 14.9\%, PCA3 had 9.2\%, PCA4 7.8 (Table 5). According to [18] report the first principal component was considered which explained $57.4 \%$ of the variation observed. About $88.6 \%$ of the total variability of 62 chickpea genotypes which is evaluated for 11 quantitative traits was explained by the first three principal components [5].

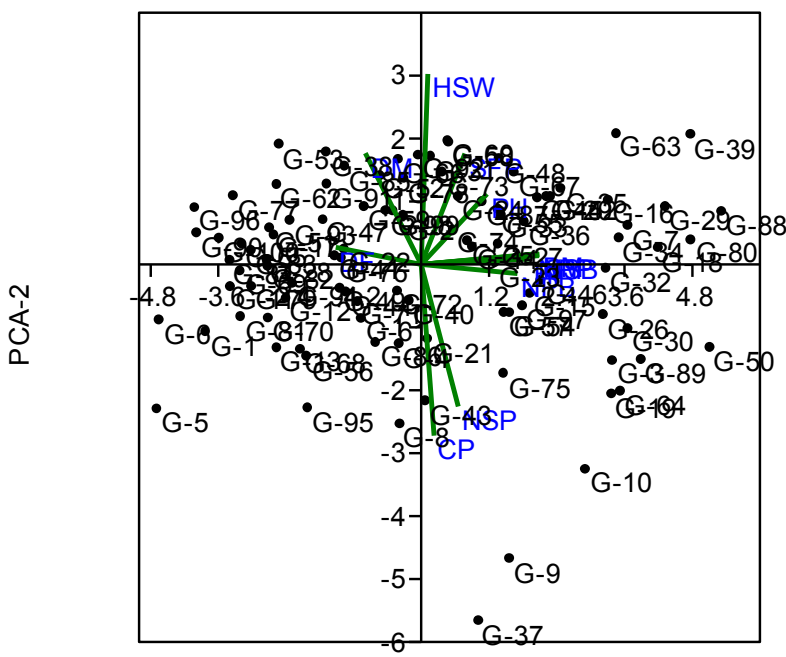

PCA-1

Figure 4. Biplot of PCA1 and PCA2 showing the overlay of 100 genotypes and the 13 studied traits.

Table 5. Vector loadings and percentage explained variation by the first four PCs.

\begin{tabular}{lllll}
\hline Eigenvectors & & & & \\
\hline characters & PCA 1 & PCA 2 & PCA 3 & PCA 4 \\
\hline Days to flowering & -0.28075 & 0.04999 & 0.12578 & 0.63391 \\
Days to maturity & -0.18339 & 0.32644 & 0.62095 & 0.30031 \\
Seed filling period & 0.14316 & 0.32619 & 0.57997 & -0.46201 \\
Plant height & 0.21446 & 0.20712 & -0.12539 & 0.42723 \\
Number of primary branch & 0.31426 & -0.02652 & 0.00829 & 0.25527 \\
Number of secondary branch & 0.38464 & 0.02581 & 0.03960 & 0.05348 \\
Number of pod per plant & 0.36746 & 0.02992 & 0.04833 & 0.06441 \\
Number of seed per plant & 0.12032 & -0.41611 & 0.40159 & 0.08335 \\
Biomass & 0.38357 & 0.03203 & 0.04034 & 0.06323 \\
Harvest index & 0.35498 & 0.01542 & -0.04762 & 0.04875 \\
Hundred seed weight & 0.02097 & 0.55884 & -0.20404 & 0.06172 \\
Grain yield & 0.38678 & 0.02935 & 0.01844 & 0.06368 \\
Protein content & 0.04099 & -0.50181 & 0.18815 & 0.13651 \\
Eigen value & 6.43 & 1.93 & 1.2 & 1.02 \\
proportion & 49.5 & 14.9 & 9.2 & 7.8 \\
cumulative & 49.5 & 64.5 & 73.7 & 81.5 \\
\hline
\end{tabular}

Note: PCA- principal component analysis.
Above ground biomass, number of secondary branches, number pod per plant and harvest index explained the highest variation on PCA1 (Table 5). Days to maturity, seed filling period, hundred seed weight and grain yield explain the highest variation on PCA2. Highest contributors for explained variance in PCA3 include days to maturity, seed filling period and number of secondary branch, while in PCA4, days to flowering, days to maturity, plant height, number of primary branch and number of seed per pod. Days to flowering was loaded negatively on PCA1, while number of seed per pod on PCA2. Hundred seed weight and seed filling period loaded negatively on PCAA3 and PC4 respectively. Hence due attention should be provided for traits responsible for the highest explained variance primarily on PCA1.

Principal component analysis (PCA) reduces a larger number of variables to a smaller number of factors and it is non-dependent procedure. The goal is dimension reduction. In this new reference frame, note that variance is greater along the $\mathrm{x}$ axis than it is on the $\mathrm{y}$ axis. Also note that the spatial relationships of the points are unchanged; this process has merely rotated the data. Finally, note that our new vectors, or axes, are uncorrelated. To select a subset of variables from a larger set, based on which original variables have the highest correlations with the principal component. The characters contributing the maximum to the divergence should be given greater emphasis for deciding the type of cluster for purpose of further selection and the choice of parental lines in hybridization [7].

\section{Conclusion and Recommendations}

The present analysis of variance revealed highly significant differences among genotypes for all observed traits, which indicated a considerable amount of variability present under examined materials. All the 100 genotypes were grouped into 9 clusters based on genetic divergence $\left(\mathrm{D}^{2}\right)$ analysis. Cluster VII and II were the largest with 24 and 18 genotypes followed by clusters XIII containing, 17 genotypes. The principal components are linear combinations of the original variables weighted by their contribution to explaining the variance in a particular orthogonal dimension. Consequently the total variance of $81.5 \%$ of PCA value was brought from 4 PCs, however the largest variation (49.5\%) brought from PCA-1.

The cluster analysis classified the 100 chickpea genotypes into nine separate clusters, exhibiting that hybridization of genotypes across clusters could lead to increase in heterosis in cross progenies. Cluster IX comprise higher grain yield, above ground biomass, number of pod per plant and plant height, while the highest flowering date and maturity date was from cluster I and cluster IV respectively. Cluster VII had genotypes that contain the largest seed weight, while the largest seed filling period was from cluster IV. Hybridization among the genotypes from these clusters which showed maximum distance might produce high yielding varieties having broad genetic base. In general the genotypes JV-11, 
IE-16-059/1， iccx-090013-f2-p215-BP，DZ-2012-CX-0028, iccx-060045-f3-p5-BP, iccx-060039-f3-p182-BP may serve as potential parents for grain yield. IE-16-109/2, iccx0900013-f2-p107-BP, icc-6279, JG-62, icc-15614, IE-16$059 / 2$ can be also a parental line for earliness, while iccx090013-f2-p265-BP, iccx-090013-f2-p107-BP, iccx-090013f2-p103-BP, iccx-090013-f2-p215-BP for hundred seed weight. IE-16-109/2, icc-14778, icc-510, DZ-2012-CK-0253, icc-5135 also be a potential parental line for quality character of crude protein. Generally genotypes listed above may serve as a parental lines for hybridization program in the improvement of chickpea grain yield and its contributing trait

Information on the relative magnitude of different sources of variation among different genotypes for several traits helps in the measurements of their range of genetic diversity. The genetically diverse genotypes are likely to produce heterotic effect and superior segregate when incorporated in hybridization to hasten crop improvement program.

Looking the genetic variability and association of studied characters in the target genotypes of chickpea in the present study together with literatures, following suggestions were made;

The genetic variability for different characters should be exploited further using much more genotypes to know more about the existing level of diversity. The characters showing high heritability along with high GA should be given due attention in the development of desirable genotypes through simple selection. Genotypes from different clusters, identified for a specific character may be used as parent for breeding program with an objective to improve the specific traits.

\section{Acknowledgements}

A successful venture is not only efforts of an individual but also with the help of eminent persons. Words would probably be insufficient to express the depth of my feelings of gratitude to respect my father Ato Tsehaye Kidea, my mother W/ro Dejitinu Asimare and my brothers Dereje Tsehaye, without those unstinted support and guidance this paper would probably be incomplete.

I also express my heartiest gratitude to Mr. Aragaw Amare for his overall field managment and data collection, financial support rendered by Gondar Agricultural Research Center, supplying the seed of genotypes of chickpea by Debre Zeit Agricultural Research Center and providing necessary facilities for carrying out quality analysis by Ethiopia Institute of Agricultural Research.

\section{References}

[1] Aliu, S., Kaul, H. P., Rusinovci, I., Shala-Mayrhofer, V., Fetahu, S., \& Zeka, D. (2016). Genetic diversity for some nutritive traits of chickpea (Cicer arietinum L.) from different regions in Kosova. Turkish Journal of Field Crops, 21 (1), 156-161. https://doi.org/10.17557/tjfc.57905.
[2] Baranwal, D. (2016). Assessment of genetic diversity based on cluster and principal component analyses for yield and its contributing characters in bitter gourd. International Research Journal of Plant Scince 2 (6): 126-133.

[3] CGIAR. (2010). Pulses Value Chain in Ethiopia. Sustainable Solution for Ending Hunger and Poverity, 1-44.

[4] Farshadfar, M., \& Farshadfar, E. (2008). Genetic Variability and Path Analysis of Chickpea (Cicer arientinum L.) Landraces and Lines, (December). https://doi.org/10.3923/jas.2008.3951.3956.

[5] Ghafoor, A., Gulbaaz, F. N., Arshad, M. (2003). Interrelationship between SDS-Page markers and agronomic characters in chickpea (Cicer arietinum L.). Pakistan J. Bot., 613-624.

[6] Halluer, A. R. and Miranda J. B. (1988). Quantitative Genetics in Maize Breeding (second ed.), Iowa State University Press, Ames, IA, USA pp 315-356.

[7] Jagadev P. N., S. K. M. and L. D. (1991). Genetic divergence in rape mustard. The Indian Journal of Genetics and Plant Breeding, 465-467.

[8] Jakhar, D. A. N. S. (2014)."Genetic diversity studies in chickpea (cicer arietinum 1.)" master of science (agriculture)"genetic diversity studies in chickpea (cicer arietinum 1.) " master of science (Agriculture), 722.

[9] Jing, R. A., Vershinin, J. Grzebyta, P. Shaw, P. Smýkal, D. Marshall, M. J. Ambose, T. N. Ellis and A. J. Flavell (2010). The genetic diversity and evolution of field pea studied by high throughput retrotransposon based insertion polymorphism (RBIP) marker analysis, BMC Evolutionary Biology, 10, pp. 1-20.

[10] Kaiser, H. F. (1960). The application of electronic computers to factor analysis. Educational and Psychological Measurement Karaoz (Vol. 20, p. 141-151.).

[11] Mahalanobis, P. (1936). On the generalised distance in statistics. Proceedings National Institute of Science, India. Retrieved from Http://Ir. Isical. Ac. in/Dspace/Handle/1/1268., (Vol. 2,), 49-55.

[12] Mahalanobis, P. C. (1936). the Generalized Distance in Statistics. In Proceedings of the National Institute of Science of India, (Vol. 2, p. 49-55.).

[13] Parashi, V., Lad, D., \& Mahse, L. (2013). Genetic diversity studies in chickpea (Cicer arietinum L.). A Quarterly Journal, 7 (09), 2757-2763. Retrieved from http://ijpp.indianjournals.com/ijor.aspx?target=ijor:bil\&volum $\mathrm{e}=10$ \&issue $=1 \mathrm{~b} \&$ article $=047$

[14] Rao, C. R. (1952). Advanced Statistical Methods in Biometrical Research. Johan Willy and Sons.

[15] Upadhyaya, H. D., Thudi, M., Dronavalli, N., Gujaria, N., Singh, S., Sharma, S., \& Varshney, R. K. (2011). Genomic tools and germplasm diversity for chickpea improvement. Plant Genetic Resources: Characterisation and Utilisation (Vol. 9). https://doi.org/10.1017/S1479262110000468.

[16] Vijayaraje, R., Krishi, S., Vidyalaya, V., \& Gwalior, M. P. (2015). Study on Genetic Divergence in Chickpea (Cicer arietinium L) Submitted to the In Department of Plant Breeding and Genetics Rajmata Vijayaraje Scindia Krishi Vishwa Vidyalaya, Gwalior. 
[17] Wossen, T. (2017). Determination of optimum rates of nitrogen and phosphorus fertilization for white cumin, 7 (2), 460-463.

[18] Zhou, M., \& Ambev, K. I. (2012). determine how chickpea genotypes react to high temperatures and how they can be used in the improvement program for elevated temperatures, 26 (4), 1-82. https://doi.org/10.16528/j.cnki.221054/f.2015.05.004. 